\title{
Respuesta crítica a "Nota sobre la publicación Teología Política del Reverendo Padre Ignacio Ellacuría, S.J."**
}

\section{Ignacio Ellacuría}

\section{Sobre la autoridad de la 'Nota'}

1.1. El P. Freddy Delgado, Secretario General de la Conferencia Episcopal de El Salvador, me remitió el día 28 de febrero la 'Nota' con la siguiente advertencia: "Me permito enviar a Ud. fotocopia del documento que ha enviado a esta Secretaría General de la Conferencia Episcopal la Nunciatura Apostólica (Prot. 000442, Arch. CEDES), titulado [...] para su conocimiento". Por esta comunicación conocía yo la fuente inmediata, la Nunciatura, pero quedaba completamente a oscuras sobre el valor doctrinal y la autoridad de la 'Nota' que se me remitía puramente para mi conocimiento.

1.2. En el Boletín n. ${ }^{\circ} 34$ de la CEDES, p. 3 , se daba a la publicidad toda la 'Nota' con la siguiente presentación: 'La Nunciatura Apostólica envió a la Santa Sede el libro Teología Política... para que fuese criticado por un teólogo de autoridad".

1.2.1. Aquí se avanza más de cara al público, cosa que no se hizo en la comunicación que me llegó. La promotora es la Nunciatura, aunque no se sabe si por su propia iniciativa o a reclamo de terceros; el lugar de origen de la crítica es Roma; el crítico es un teólogo de autoridad, encargado para ello por la Santa Sede.

1.2.2. La redacción del Boletín es en sí cuidadosa, pero para el público se presenta con un grave equívoco, que ya ha sido aprovechado para fines políticos,

* Escrito inédito del P. Ignacio Ellacuría, fechado el 24 de abril de 1974. 
lo cual obligaría a la Nunciatura o, en su defecto, a la Conferencia Episcopal, a aclarar la cuestión. Parece ser una obligación de justicia tanto por lo que toca a mi nombre como por la utilización que del asunto pueden hacer los interesados en hacer política tanto a nivel privado como a nivel oficial.

1.2.3. La aclaración de este punto fue pedida en carta mía de 7 de marzo a la Secretaría de la CEDES. Todavía no se ha hecho.

1.2.4. En cuanto se puede deducir de todo esto la conclusión es que la 'Nota' en cuestión no tiene más autoridad que la del teólogo que no da su nombre y la de las razones que aporta. Afortunadamente, como luego se verá, la Santa Sede, ni siquiera la Secretaría de Estado, quedan comprometidas con los razonamientos del teólogo. Con todo, sí son responsables de la elección del teólogo. Y son negativamente responsables por dar curso a un escrito, cuya valoración haré más tarde.

\section{Sobre la estructura formal de la 'Nota'}

2.1. La 'Nota', que en italiano se llama "Appunto", está redactada en siete páginas holandesas, que responden a seis del texto italiano, traducido en un punto esencial con un grave error como luego mostraré, error que ha sido reproducido tanto por el Boletín de la CEDES como por otros órganos de difusión. Lo cual prueba la poca seriedad del traductor, del transmisor de la 'Nota' a la CEDES y del responsable de la publicación del Boletín en cuestión.

2.2. Ni las hojas del original ni las hojas de la traducción tienen membrete alguno que las identifique. Están escritos sobre papel blanco y están sin firmar.

2.2.1. En el texto italiano hay, al menos, ocho correcciones a mano y otras ocho tachaduras o intercalación de palabras. Lo cual no prueba, salvo tal vez dos intercalaciones en la última página, ninguna otra mano que la del teólogo, pero sí prueba la autoridad del documento. No es de creer que la Santa Sede, tan cuidadosa en la presentación tipográfica de sus comunicados, haya sido en esta ocasión tan descuidada. Tal vez se puede desprender de esta presentación la poca seriedad y autoridad de la 'Nota' en cuestión.

2.2.2. En el texto español que la Nunciatura mandó a la CEDES podemos ver no menos de trece tachaduras y correcciones. Igualmente, está sin firma responsable y sin membrete alguno. Aquí la explicación es más difícil de encontrar, pero tal vez sea una nueva prueba de que en el documento mismo no hay compromiso de la Nunciatura.

2.3. La 'Nota' tiene una primera parte dedicada a los méritos de la publicación. Están recogidos del prólogo que el P. Ramón Vega antepuso a la publicación, pero están confirmados y documentados por el autor de la 'Nota'. Ocupan página y media. Después vienen los reparos, que ocupan cinco páginas, y finalmente una "Conclusión" de pocas líneas. 
2.3.1. A1 entrar en la segunda parte dedicada a los "Reparos" (Riserve) introduce el tema con un texto mío, a continuación pone un "Juicio complexivo". Después se rompe la unidad formal del escrito, pues se introducen unas "Observaciones particulares" que están montadas sobre el primero de los trabajos, sin citarlos como trabajo autónomo, para a continuación ir criticando trabajo por trabajo no sabe uno si como confirmación del "Juicio complexivo" o como críticas aparte, saltándose el artículo "Liberación: Misión y Carisma de la Iglesia Latinoamericana", que pasa sin crítica expresa, y cosa más de notar pues en la conclusión se dice que este tipo de escritos no es bueno para Latinoamérica. Ya desde este punto de vista meramente formal se ve con qué poco rigor metodológico está escrita la 'Nota', punto que comprobaremos hasta la saciedad en posteriores análisis.

2.3.2. Las citas a las que el autor acude son una de la Humanae vitae (p. 5), una de la Pacem in Terris (p. 5) y una referencia a la Lumen Gentium y a la Gaudium et Spes (p. 5). En la p. 6 hay una cita de Efesios y otra de Hebreos, ambas en latín, es decir, no en su original griego ni en su traducción al italiano o español (la observación es significativa para mostrar el tipo de teólogo); hay asimismo una cita de San Agustín y otra de Santo Tomás. Cita finalmente en la p. 7 a la Conferencia Episcopal de México, con referencia a la Gaudium et Spes, Populorum Progressio, Mater et Magistra, II Conferencia CELAM, documentos que tanto en el texto italiano como en el español unas veces se subrayan otras no, como prueba de la errática metodología del escrito. En la p. 2, como alabanza del texto, se citan a la Gaudium et Spes y la Populorum Progressio (aquí sí subrayadas). Y en la p. 6 se cita a Pío X y al único teólogo o biblista, Garofalo, que aparece en toda la refutación. Este tipo de citas, por su presencia y, sobre todo, por sus clamorosas ausencias sobre estos temas de 'teología política', muestran el status intelectual del teólogo en cuestión. Quien sabe quién es Garofalo, sabe de dónde procede nuestro teólogo. (Por dar un dato contribuyó con Pietro Parente y Antonio Piolanti a la segunda edición de un Diccionario de teología dogmática, allá por 1945).

\section{Sobre los méritos reconocidos en la 'Nota'}

3.1. Recoge lo que ha dicho el P. Ramón Vega, a quien tácitamente le reprocha haberlos señalado "sin reserva alguna".

3.2. En lo que el teólogo añade por su cuenta como confirmación y documentación, se citan algunas afirmaciones mías, pero sin tocar ni de lejos el verdadero sentido de mi trabajo.

3.3. Se pone como prueba de los méritos el que yo afirme que la 'teología del desarrollo' no baste y el que sostenga, según el teólogo, lo siguiente que él parece aprobar: "es necesaria la 'teología de la revolución', de la Cruz, de la Sangre, 
es decir del sufrimiento que libere a los responsables de la 'violencia de la injusticia' y así los salve de la cólera divina" ('Nota', p. 2).

3.3.1. Según el crítico, aquí defiendo una ‘teología de la revolución' correcta. ¿Por qué después en la p. 3 la condena y la equipara a la 'teología de la violencia'?

3.3.2. El teólogo debía haber notado, por otra parte, que el término 'teología de la revolución' está usado en un sentido impropio, únicamente para contraponerlo a la 'teología del desarrollo'. Si se hubiera detenido en el análisis serio de los trabajos, habría podido reconocer en estas páginas el estrato más antiguo. Pero estos perfiles no se pueden pedir a un crítico tan precipitado.

\section{Sobre el 'Juicio complexivo' y las 'Observaciones particulares' (pp. 2-4 de la 'Nota')}

4.1. El autor inicia esta sección con una larga cita mía, sacada completamente de contexto. Dice el autor: "el mismo P. E. se da cuenta de que su escrito es objeto de posibles críticas, por parte de opiniones opuestas". Como prueba trae una nota que yo añado a un determinado texto. Hay aquí una extrapolación injusta y doble: en primer lugar, refiere a todo mi escrito una observación que yo hago para un pasaje muy determinado; $y$, en segundo lugar, malentiende el sentido de mi observación al dejar de lado su contexto preciso.

4.2. A continuación propone las dos críticas principales que "parece se pueden hacer" (due sono le critiche principali che sembra poteri fare alla interpretazione del P. E.). Ya veremos cómo el autor concluye de este modesto "parece se pueden hacer'.

4.2.1. Dice así la primera crítica: "si es cierto que él no reduce la redención de Cristo al problema de la liberación de los individuos y de la sociedad latinoamericana del 'pecado del mundo' moderno, es decir, de la 'violencia institucionalizada' propia del sistema capitalista; es también cierto que él exagera este aspecto de la 'salvación en la historia' no sólo descuidando, sino dejando en penumbra y desvalorizando el aspecto individual, espiritual, de la redención de Cristo. Por tanto son (el texto italiano dice tan sólo 'vengono') menospreciados: la fe como adhesión a las verdades eternas, meta-históricas; la esperanza en los bienes sobrenaturales, futuros; la religión como culto de Dios y práctica de los sacramentos; la práctica de las virtudes cristianas: del amor de Dios y el amor sobrenatural del prójimo; la paciencia; la práctica de las bienaventuranzas evangélicas".

4.2.1.1. Hay en el párrafo una serie de graves defectos formales. ¿Cómo se prueba que desvalorizo el aspecto individual, espiritual de la redención de Cristo? Habría de ser cierto que yo exagerara el aspecto de la salvación en la historia y de ahí no se seguiría que se desvalorizara ese aspecto individual. Desvalorizar es un verbo activo: ¿dónde está activa y positivamente desvalorizado el aspecto 
individual de la redención de Cristo? ¿Qué se entiende por redención de Cristo: la que él llevó a cabo o la que con él participan los cristianos? Es claro que a ambos aspectos doy cabida en mi trabajo, por más que no sea ese el tema al que están dedicados.

Por otro lado, ¿cómo concluir de su acusación infundada que menosprecio toda la serie de cosas que me atribuye? Si en el italiano dice "quindi vengono deprezzati", la traducción enviada desde la Nunciatura y hecha pública dice "por tanto son menospreciados". Mal quedan la lógica y la verdad en el texto italiano, pero mucho peor en el castellano. El autor deduce que son despreciados por mí una serie de valores cristianos. Si su conclusión fuera lógica, debiera haber mostrado en qué parte de mi escrito están menospreciados, pero ni una sola prueba de esto da.

4.2.1.2. Dice el autor que exagero el aspecto de la 'salvación en la historia'. Lo dice, pero no lo demuestra. Con ello ignora y pasa por alto lo que es esencial en mi trabajo: la salvación en la historia es el signo de la plenitud de la salvación que es meta-histórica ( $c f r$. entre otros muchos pasajes: "la liberación históricosocial del pecado como signo de la credibilidad de la misión de la Iglesia", pp. 51-59; "la exigencia absoluta de justicia [como] signo de credibilidad de la Iglesia", pp. 59-63). No haber captado esta teología del signo, que domina toda la publicación (que como diré más tarde pertenece a lo que debe entenderse hoy por teología fundamental), supone una gravísima ligereza en la lectura y en el juicio subsiguiente. Todo lo que se presenta como salvación en la historia (lo cual no equivale sin más a la salvación de la historia) se busca como signo de la historia de la salvación, viene de ésta y va a ésta. En mi trabajo se trata de demostrar la conexión entre el signo y lo que le constituye en signo.

4.2.1.3. Dice el autor que dejo en penumbra y desvalorizo el aspecto individual, espiritual de la redención de Cristo. Su terminología es aquí, por decir poco, inexacta y desusada a la altura de la teología actual. Mi trabajo, aun dentro de la perspectiva propia de la Teología política, pone bien en claro y valoriza el aspecto personal y salvífico de la redención. En mi trabajo no se habla de la redención en su sentido pleno y teológico, porque no es ese el tema; se habla de lo que debe ser la redención cristiana de la violencia. Mi crítico cae aquí en un quid pro quo. Lo que sí hablo es de la misión de Cristo, aunque de un aspecto de ella. Y de ella indico tanto su dimensión personal como su dimensión salvífica. Entre otros pasajes, véase este: "El amor de Dios en los hombres y a los hombres en Dios es un elemento esencial y diferenciativo del Cristianismo. La revelación en el Hijo encarnado del Dios Padre, que ama al mundo hasta entregarle su propio Unigénito es uno de los puntos esenciales del mensaje cristiano; pero es asimismo esencial la convicción de que el amor de Dios pasa a través de los hombres. El hacerse hombre del Hijo, para que los hombres alcancen definitivamente su ser hijos de Dios, tiene una significación fundamental en el mensaje 
cristiano: el Dios lejano pasa por el hombre cercano para mediar y comunicar su presencia (Teología política, p. 64).

4.2.1.4. Dice el crítico que menosprecio "la fe como adhesión a las verdades eternas meta-históricas". Esta acusación debería haberla probado, o mostrado dónde se da el menosprecio general a esas verdades, mostrando algunas de esas verdades que yo haya menospreciado. De lo contrario su afirmación resulta gratuita e insidiosa. Le recomiendo que analice cuántas verdades de esas son afirmadas o supuestas en mi trabajo y encontrará un gran número de ellas.

Por otro lado, la concepción de la fe que apunta esa frase crítica es una concepción parcializada de la fe (cfr. R. Aubert, 'La Constitution 'Dei Filius' du Concile du Vatican", en De Doctrina Concilii Vaticani Primi, Libreria Editrice Vaticana, 1969, pp. 46-121; Cardenal Bea, Vaticano II, la doctrina del Concilio Vaticano sobre la Revelación, Madrid, 1967, especialmente pp. 100-101; R. Schnackenburg, J. Truetsch y W. Pannenberg, en el artículo "Glaube" del LThK; y J. Alfaro, Adnotationes in tractatum de virtutibus [ad usum privatum], Roma, 1957).

4.2.1.5. Parecidas cosas tendría que decir de toda la serie de acusaciones infundadas que el crítico me hace a continuación. Sobre la esperanza y su carácter metahistórico, véase por ejemplo este texto mío: 'La misión de la Iglesia en el anuncio del Evangelio no se reduce a la tarea apuntada en las páginas anteriores... Nuestra exposición ha sido forzosamente limitada y ha acentuado aque1los aspectos que corresponden a la Iglesia como signo de credibilidad ante un mundo que busca la salvación y que duda vehementemente de que la salvación anunciada por la Iglesia sea la salvación que él está necesitando... Hoy se habla de la función crítico-social de la Iglesia a través de la reserva escatológica; se habla de la Iglesia como instancia profética; se habla de la Iglesia como lugar de la esperanza activa de la promesa. La Iglesia cumplirá con su misión solo si se mantiene como fiel esposa de Jesucristo" (Teología Política, p. 68).

4.2.1.6. Sobre la religión como culto de Dios y práctica de los sacramentos diré que hay una publicación mía donde expongo algunos puntos. Ahí debiera acudir mi crítico y no a un trabajo en el que no se trata del tema. Sin embargo, no estará de más añadir que la religión propugnada en mi escrito es condición fundamental del culto; sin ella este arrancaría de los profetas y del Nuevo Testamento los más arrebatados reproches.

4.2.1.7. Lo que se me acusa del amor de Dios y del amor sobrenatural de los hombres es ya el colmo de la irresponsabilidad. No tengo sino que referirme a todo mi escrito para ver la sinrazón y la subjetividad de mi adversario.

4.2.1.8. Lo mismo debe decirse de la paciencia. ¿No alabo, acaso, como solución cristiana la de los hermanitos de Foucauld, porque testimonian, "el aspecto transcendente del Cristianismo tal como se refleja en el Cristo paciente, que por 
amor se entrega silenciosamente a la muerte con la esperanza cierta de una resurrección salvadora?" (TP, p. 124).

4.2.2. La segunda crítica principal dice así: "El P. E. no sólo insiste excesivamente en la redención de Cristo, que implica el rechazo de toda resistencia activa a la injusticia; sino que admite la "teología de la revolución", la "teología de la violencia" (es decir de la fuerza o resistencia activa), al menos "en ciertos casos límites", cuando las otras dos vías cristianas por la redención de la violencia, la de los hermanos de Foucauld y la de Luther King, no son suficientes, sino que se exige de la tercera, la de Camilo Torres (prescindiendo, sin embargo, de determinadas soluciones técnicas y deteniéndose en las directivas fundamentales: p. 124)" ('Nota', p. 3).

4.2.2.1. Tal es el texto que fue enviado a la CEDES, que esta publicó en su Boletín, así como [en] Orientación. El texto tal como está no hace sentido y se contradice con el párrafo inmediatamente anterior. Pero esta gravísima deficiencia no está en el original italiano, donde se lee: "Non solo il P. E. non insiste eccessivamente sulla redenzione di Christo..." ('Appunto', p. 3).

Este es el error al que aludía en 2.1. y que prueba la ligereza del traductor, del transmisor, del receptor y del publicador, pues se trata de un punto fundamental. No es, en efecto, un error casual, sino tercamente repetido por falta de rigor $y$ de atención. Dejemos, además, de lado la sintaxis del párrafo, mala en italiano y en español, y la mala traducción de "dos vías cristianas por la redención de la violencia", donde en lugar de 'por' debe decir 'para'. Subrayo estos detalles para probar la irresponsabilidad del escrito y de sus publicadores. Vayamos a la acusación misma.

4.2.2.2. El crítico romano confunde 'resistencia activa' y 'fuerza'. Esto indica cuán lejos está de conocer, siquiera por encima, el tema. Supone también una gran ligereza en la lectura de mi texto, donde están claramente diferenciados. Al confundir estos dos términos, no sé cómo le puede parecer mal la 'resistencia activa', tan defendida por la más clásica teología, tanto en el caso de la defensa personal como en el de la guerra. Según esta lógica los clásicos serían partidarios de la teología de la revolución y de la teología de la violencia.

4.2.2.3. Me acusa de no insistir excesivamente (debidamente, querrá decir) en la redención de Cristo que implica el rechazo de toda resistencia activa. Yo no creo que la redención de Cristo implica el rechazo de toda resistencia activa, porque de lo contrario todos los defensores clásicos de la resistencia activa estarían contra la redención de Cristo. Porque se trata de resistencia activa a la injusticia y están de por medio todas las teorías - no necesariamente compartidas por mídel agresor injusto. Más aún, yo he escrito como conclusión de mi trabajo sobre la violencia: "Todas las reflexiones han surgido de la reflexión sobre la realidad concreta en la que vive, sobre todo el Tercer Mundo, y van dirigidas a construir 
el marco teórico en el que poder enmarcar una concreta acción cristiana que combata contra la violencia de la injusticia, contra el pecado de la violencia. Un combate que deberá tener muy en consideración dos realidades de extraordinaria importancia: no todo lo que hay en las estructuras reinantes es malo, ni como estructura ni como logro personal; segunda, el mensaje cristiano exige el intentar el salirse del esquema violencia-resistencia por la fuerza lo antes posible, porque en esa lucha, aun entendida como medio, se corre el peligro inminente de perder la esencia misma del Cristianismo. No solamente el pecado de la violencia es contra el espíritu evangélico, sino también la resistencia a la violencia, si es que se toma como actitud definitiva o actitud radical o si es que se deja arrastrar por la dinámica de esa resistencia en vez de dominarla y orientarla. La redención cristiana no cobra su fuerza del odio. Debe vivir del amor, bien que de un difícil amor" (TP, pp. 126-127, con dos referencias a Pablo VI y al Cardenal Lercaro). ¿Se me puede acusar entonces [de] que defiendo una teología de la revolución o una teología de la violencia?

4.2.2.4. Es falso que yo exija la solución de Camilo Torres. Esta es una acusación injusta contra la que protesto enérgicamente y pido justa reparación. Ahí el crítico romano está cometiendo violencia contra el texto y contra mí. Debe saberlo, y si no él desde Roma, sí los que están aquí, que acusarme de eso es acusarme de un delito político, que me puede traer graves consecuencias y acusación de la que ya se han aprovechado plumas interesadas del país. Primero, purifico la solución de Camilo Torres de todos sus accidentalismos históricos; segundo, digo que deja oscurecidos aspectos fundamentales del mensaje cristiano; tercero, digo que no me parece que los niega forzosamente, aunque corre el grave peligro de hacerlo; cuarto, digo que es una tentación; quinto, enumero un principio general: "ahora bien, hay tentaciones que deben afrontarse, aun con grave riesgo, si es que están en juego valores superiores y la situación es una situación límite" (TP, p. 124); sexto, puntualizo el sentido apelando a la legitimidad de la guerra. Y acabo diciendo: "Decíamos al iniciar este apartado que su intento no era el de dar soluciones prácticas, sino el de apuntar tres estilos diferentes (Foucald, King, Torres) de enfrentar con espíritu redentor el trágico pecado de la violencia. Brevemente han quedado insinuadas parcialidades y deficiencias de cada uno de los tres estilos. Parcialidades y deficiencias que muestran, ante todo, la necesaria ambiguiedad de toda solución que se enfrenta con un pecado encarnado en personas y objetivado en estructuras sociales; que muestran, también, cómo la conciencia cristiana ha de seguir buscando vigilantemente una solución nueva, a la vez puramente cristiana y urgentemente eficaz, a un problema que no admite dilación" (TP, pp. 124-125). Aquí hay suficientes elementos de matización para que el crítico romano y sus secuaces acríticos no simplifiquen mi posición, diciendo que admito una teología de la revolución o de la violencia, tal como parece él entenderlas. 
4.2.2.5. Por otro lado, recuérdese que el crítico romano parecía alabar la teología de la revolución que me atribuía, cuando confirmaba mis méritos (cfr. supra 3.3.1).

4.2.3. ¿Qué queda, por tanto, de las dos críticas principales, una vez sometidas a un ligero análisis? Yo dejo que el lector saque las debidas consecuencias sobre la calidad intelectual del crítico, sobre la intelección que ha logrado de mi texto, sobre la ligereza de sus conclusiones y sobre la posible manipulación a que puede someterse con facilidad todo este asunto. Lo triste es que de una u otra forma estén en juego la Nunciatura, la Santa Sede, la CEDES, y también los derechos fundamentales de una persona y de un cristiano. No se olvide que de este asunto se ha hecho publicidad y publicidad política, so capa de que hay intereses religiosos de por medio. ¿No hubiera sido mejor entender el texto en lo que dice y quiere decir, más bien que el de buscar dónde puede ser malentendido?

4.3. La última parte de esta sección va dedicada a unas "observaciones particulares", donde por acumulación de afirmaciones que le parecen criticables, el teólogo romano pretende encontrar documentación para su juicio general.

4.3.1. Todas estas afirmaciones están tomadas del artículo primero de mi trabajo, y como ya lo indiqué (cfr. 2.3.1) en discontinuidad metodológica con el resto de su crítica.

4.3.2. Aun si se admitiese que las afirmaciones transcritas por el crítico necesitaran mayor aclaración - aclaración que está dada por el conjunto del trabajo, del que han sido entresacadas-, esto no serviría de documentación del juicio general. Falla de nuevo aquí la lógica de mi adversario. Lo cual no podía ser de otra forma, porque las observaciones están tomadas del primer trabajo y el juicio general está montado fundamentalmente sobre trabajos posteriores.

4.3.3. Como el crítico no se ha tomado el trabajo de interpretar las frases que cita, ni de leerlas en su contexto, ni de ponerlas en relación con su juicio general, no haré referencia explícita a ellas. Baste con un par de indicaciones para que se vea su modo proceder.

4.3.3.1. Donde yo digo: "Y podría aventurarse la sospecha de que el fracaso no está siempre en lo que esa teología dice (la teología clásica repetida hoy) sino más bien en lo que deja de decir en aquello que dice, esto es, en que no alcanza a mostrar la dimensión secular de todas y cada una de las afirmaciones teológicas", el crítico romano mutila el texto y quita todo su sentido de precisión y matización cuando transcribe selectivamente lo siguiente: "el fracaso es debido sobre todo al hecho de que ella no alcanza la dimensión secular de todas y cada una (subrayado que me atribuye gratuitamente) de las afirmaciones teológicas" ('Nota', p. 3). Obsérvese lo que ha quitado y se verá cuál es su objetividad y se podrá sospechar qué intereses mueven todo esto. 
4.3.3.2. Donde yo digo: "Se puede admitir que el depósito de la fe está concluso, pero... está concluso como sistema de posibilidades; ahora bien, la historia es precisamente actualización de posibilidades. Sólo el fin de la historia actualizará toda la revelación, y lo que es revelación solo como posibilidad no es todavía actual revelación. Por esta razón es a la historia que los hombres hacen, a donde debe volverse el cristiano y el teólogo para escuchar el dato objetivo y total de la revelación", el crítico romano retira tanto mi afirmación del carácter concluso del depósito de la fe como la explicación de por qué se requiere la historia para que la revelación dé totalmente de sí.

4.4. Si tomamos a una la deformación de la cita con que el crítico romano ha iniciado esta sección (cfr. 4.1), la deformación y fragilidad de todo el juicio comprensivo ( $c f r$ todos los párrafos iniciados con 4.2), y el disloque de las observaciones particulares (cfr. todos los párrafos que comienzan con 4.3), se puede deducir lo que vale su crítica tanto en cuanto al método como en cuanto a su contenido. Los que han repetido y publicado esta crítica sin comprobar su fundamentación, indican un modo de proceder en cuyo análisis me parece superfluo entrar.

\section{Juicio sobre algunos trabajos en particular}

5.1. Carácter político de la misión de Jesús.

5.1.1. También aquí la metodología del crítico romano es errática. Transcribe textos sin contexto. Unas veces los acumula sin más y otras los critica explícitamente. Atendamos a estas críticas.

5.1.2. "Desvaloración de la teología cristológica patrística y del Concilio de Calcedonia" ('Nota', p. 4). Afirma, pero no prueba. Mi texto dice así: "Se logró así una respuesta histórica y también unos logros permanentes pero no definitivos; pensemos, por ejemplo, en Calcedonia. Pero esto no quiere decir ni que con ello se ha dicho todo lo más sustancial de una cristología, ni aún siquiera que en la pura línea de la interpretación intelectual no se pueda avanzar más" (TP, p. 13).

5.1.3. "Desvaloración del aspecto ontológico-sobrenatural del misterio de la Encarnación en confrontación con su aspecto soteriológico-histórico ('Nota', p. 4). Digo expresamente: "este no es un planteamiento meramente funcionalista, ni menos profundo que el anterior" (TP, p. 13). Para nada contrapongo temáticamente lo ontológico-sobrenatural con lo soteriológico-histórico. Mi planteamiento va por otro camino, porque no admito el término ontológico ni menos aún la relación de lo ontológico con lo sobrenatural. La ontologización de la realidad que esto supone y la exteriorización metafísica de la historia que esto implica son, en el mejor de los casos, hipótesis filosóficas. Reducir, entonces, el pensamiento ajeno, sin entenderlo, a esquemas ya dados es una sutil forma de falsificación. Confundir interpretaciones teológicas con el fondo de la fe es un error de grandísima importancia eclesial. 
5.1.4. "Crítica de la cristología patrística acusada de apriorismo en la explicación de la autoconciencia de Cristo" ("Nota', p. 4). Para probarlo cita a medias un texto mío: "podría entonces sugerirse que Jesús fue adquiriendo conciencia plena de un ser personal pleno en la vida y por la vida en que se realizó" (TP, p. 14). Hay aquí dos problemas distintos:

5.1.4.1. Lo que digo de la exégesis patrística es que no es muy rigurosa desde el punto de vista científico, lo cual es evidente. Sus métodos no son adecuados y su conocimiento del origen mismo del Nuevo Testamento era deficiente. Negar esto es cerrarse a la evidencia.

5.1.4.2. Lo que digo de la conciencia de Cristo es hoy enseñanza común entre teólogos y exegetas. Para no ser mal interpretado aludía en mi texto a una serie de autores conforme a los cuales y basado en ellos se debía entender lo que escribía. El crítico romano no se ha tomado el trabajo de transcribirlo. Dice así: "el artículo de Vögtle, 'Exegetische Erwägungen über das Wissen und Selbstbewusstsein Christi' ...; el de Rahner, 'Dogmatische Erwägungen über das Wissen und Selbstbewusstsein Christi'...; el trabajo conjunto de los dos sobre el término 'Jesucristo' en Sacramentum Mundi...; el n. 11 de Concilium, todo él pero especialmente el boletín de Gutwenger sobre la ciencia de Cristo; el trabajo de Schnackenburg en el volumen tercero de Mysterium Salutis..." (TP, p. 14). Zanjar entonces la cuestión con una cita de Pío X no tiene sentido teológico, aunque demuestra qué tipo de teólogo ha sido encargado de juzgar mi trabajo.

5.1.5. Se me acusa de acentuar excesivamente el aspecto político de la misión de Jesús. Mi artículo está dedicado expresamente a eso, a subrayar la dimensión política, la cual naturalmente debe complementarse con otras dimensiones de la misión de Jesús, como es obvio y lo advierto repetidas veces. Por otra parte, pensar refutar lo que yo digo con las pruebas que aduce el crítico romano: que los jefes del pueblo lo condenaron por motivos religiosos, que Pilato no encontró en él ningún delito político, y que Jesús declaró que su reino no es de este mundo, es mostrar la ligereza con que se ha leído mi texto y la copiosa bibliografía que hay sobre el tema.

5.1.6. Se me acusa de admitir verdaderas tentaciones en la vida de Jesús y para contrarrestar tal afirmación se cita a Garofalo, único autor, más o menos actual, que aparece en el escrito del crítico romano. Pero la cita no viene a cuento, porque yo no he afirmado ninguna prevalencia de Satanás sobre Jesús, ni si venía de un Satanás que estaba dentro o que estaba fuera. Sencillamente no trato de nada de esto y ahí aparece otro tipo pintoresco de argumentación. Con esto no quiero decir ni por un momento que esté de acuerdo con Garofalo en su comentario de las tentaciones.

5.1.7. Se me acusa de desvalorizar el testimonio de Jesús ante Pilato. La formulación del crítico romano, metido a temas de Teología política para el Tercer 
Mundo, no puede ser más pintoresca, aquí también. Dice así: "desvalorización doctrinal-ontológica y politización del testimonio de Jesús frente a Pilato" ('Nota', p. 4). Para probar su afirmación de los cinco puntos con que explico el texto evangélico sólo me cita uno. Lo de doctrinal-ontológico no parece peregrino. Y en lo de la politización, debiera atenerse el crítico romano al status quaestionis del artículo.

5.1.8. Me acusa de "confusión entre revelación divina y reflejos benéficos de la misma..." ('Nota', p. 4). Debe querer decir en español que confundo la revelación con sus reflejos benéficos. Para probarlo trae un texto mío sin su cita correspondiente. El texto, claro está, no prueba lo que el crítico romano pretende atribuirme. Por otro lado, este tema está tan tratado en mis páginas que parece un grave error metodológico atenerse a un solo texto. De ahí que lo entienda tan mal.

\subsection{La iglesia como signo de credibilidad.}

5.2.1. Se me acusa de ceder al historicismo "no advirtiendo que la historia y el orden social debe conformarse al sobrenatural, del cual la Iglesia es custodia e intérprete" ("Nota', p. 5). En la página, a la que se refiere el crítico romano, digo: "Por tanto, no la naturaleza y el orden natural, sino más bien la historia y la ordenación social son, por lo pronto, el cuerpo mediador de Dios. Es este punto de singular importancia, porque lleva a concebir a la Iglesia no como defensora del orden natural sino como ordenadora de la realización social; la naturaleza sería signo revelador y comunicador de Dios, en cuanto elemento de la historia, lo cual no implica caer en ningún historicismo porque la identificación de naturaleza y esencia es una identificación gratuita... Dentro de la historia es la biografía de Jesús quien da la clave significativa insustituible, una clave que no por ser escandalosa a quienes habían deducido el ser de Dios a partir de la naturaleza, puede dejar de ser anunciada como tal por la Iglesia" (TP, p. 48). Tras este texto mío, que está en consonancia con el resto del escrito, uno se pregunta, primero, qué ha entendido el crítico romano de lo que estoy diciendo, y, segundo, cómo puede acusarme de lo que acusa, cuando estoy afirmando lo contrario. ¿Serán necesarios estos malentendidos cuando se remite al juicio de un teólogo romano lo que está escrito y pensado con otras categorías?

5.2.2. Me acusa de no poner de relieve que los mártires han sido signo de credibilidad de la Iglesia. El crítico romano no ha entendido que lo que mi escrito propugna es precisamente una iglesia martirial, martirial por su carácter esencial de contradictora del mundo. Parece olvidar, además, el crítico romano que las primeras oleadas de mártires de la Iglesia primitiva tienen el mismo carácter religioso-político que lo tuvo la muerte Jesús.

5.2.3. Le parece al crítico romano que mis acusaciones son muy fuertes en lo que se refiere a la Iglesia en cuanto favorecedora de la dominación y de la injusticia del mundo. Léase el primer párrafo de la p. 62 para medir lo que yo digo 
sobre este punto. Lo que ya me parece intolerable, sobre todo visto el problema desde el Tercer Mundo, es que al crítico romano le parezcan prueba de la santidad de la Iglesia cosas como las universidades y los montepíos. Esto es reírse del tema, reírse de la realidad y reírse de los muertos.

5.2.4. El crítico romano me objeta que no presento fielmente el ejemplo de Cristo frente a la injusticia humana. Para ello cita un texto mío, que en lo fundamental dice: "La lucha le costó la vida. Es este un punto en que la interpretación espiritualista del Evangelio nos ha deformado (el traductor dice mal no ha deformado, lo cual en el contexto es un contrasentido que parece no preocuparle ni a él ni a sus transcriptores) la realidad del amor de Jesús: suele decirse que Él no mató sino que se entregó a la muerte por realizar su amor a los hombres. Pero este planteamiento falsifica la realidad: ciertamente no mató, pero no hay duda de sus actitudes violentas, de su lucha incesante con los poderosos de su tiempo; más aún, no es históricamente verdadero que se ofreció como víctima por el pecado de injusticia y por la falta de amor entre los hombres, sino que fue víctima del pecado de injusticia y de la falta de amor entre los hombres. Luchó contra ese pecado y fue castigado por ellos..." (TP, p. 65). Más aún, transcrito este párrafo e intercalados unos textos de Efesios, Hebreos, San Agustín y Santo Tomas (todos en latín), concluye: “si se pone en duda el carácter 'oblativo' de la muerte de Cristo, se compromete el valor de sacrificio y por tanto el valor redentivo. Esto va contra la revelación explícita" ('Nota', p. 6).

5.2.4.1. Este es un punto que merece alguna mayor consideración por la gravedad de lo que implica, aunque sea hipotéticamente, y porque aquí estaría el fundamento de la primera crítica principal del juicio general (cfr. 4.2.1 y siguientes). Mezcla, por otro lado, dos cosas distintas: el no presentar fielmente el ejemplo de Cristo frente a la injusticia humana y el no reconocer el carácter oblativo de la muerte de Cristo. Son dos cosas distintas, de las que he tratado largamente en mi escrito la primera y no me he referido para nada a la segunda. Son dos cosas que deben diferenciarse formalmente, según lo pide el status quaestionis de mi trabajo. No estoy tratando de la redención de Cristo sino de la dimensión política de su misión.

5.2.4.2. Si presento o no fielmente el ejemplo de Cristo frente a la injusticia humana, es algo que se debe probar y no afirmar. Atiéndase a que yo manejo ahí en las referencias a Jesús lo que denomino un logos histórico sobre un punto determinado: en qué relación está la historia de la salvación con la salvación en la historia. Obviamente mucho queda por investigar aún en este campo acotado. Pero si se quiere criticarlo es menester entrar en él. El crítico romano debía haberse remitido aquí al artículo de la dimensión política del mesianismo de Jesús.

5.2.4.3. El sentido del texto que el crítico romano transcribe puede verse desde este otro texto publicado por mí: "Es cierto teológicamente que Jesús murió por 
nuestros pecados, pero es cierto históricamente que Jesús fue ajusticiado por las autoridades de su tiempo, al haber visto en él un peligro para su situación de privilegio. Murió por el pecado del mundo, pero es ese mismo pecado del mundo el que le mató. No son dos datos inconexos. Al contrario, en ellos se refleja la intrínseca relación entre la historia de la salvación y la salvación de la historia. Es la suprema fidelidad a la misión que el Padre le encomendó, lo que le llevó a la Cruz. Luchando por la historia de la salvación se encontró con su condenación histórica. Y no se arredró. No evitó el enfrentamiento...". Ahí se ve cómo lo histórico no está en oposición con lo teológico y cuál es la razón de la conexión entre ambos planos. La misión redentora de Jesús puede expresarse en lenguaje histórico - caso predominante en los Sinópticos - o en el lenguaje cúltico - caso predominante de los textos que el crítico romano alude-. No están en contradicción. No hay duda [de] que el lenguaje inicial de Jesús fue el lenguaje histórico; el lenguaje cúltico será verdadero lenguaje de Jesús, si es que vive del seguimiento histórico de Jesús y lleva a él.

5.2.4.4. Desde estos puntos de vista carece de sentido atribuirme negación alguna del carácter oblativo de la redención de Cristo. Es como querer decir que el Derecho Canónico niega la Trinidad porque no habla de ella.

5.3. Vías cristianas para una redención de la violencia y a modo de conclusión.

5.3.1. En esta parte el crítico romano recoge tan sólo los dos últimos epígrafes de mi trabajo "Violencia y Cruz". Tiene también su importancia porque supuestamente of recerían la base para la segunda crítica principal del juicio complexivo. Lo sorprendente es que en este punto, donde el crítico romano debería aportar las pruebas de su juicio complexivo, no lo hace. Veámoslo.

5.3.2. Lo primero que me censura el crítico romano es que no hago "ninguna crítica explícita a la postura 'violenta' de Torres considerando su sacerdocio, aun cuando había renunciado a sus funciones sacerdotales".

5.3.2.1. Curiosamente aquí no me atribuye nada de la teología de la revolución o teología de la violencia y se me hace una objeción de poquísima monta y que no viene a cuento. Expresamente digo: "El caso personal de Camilo está subsumido aquí en una visión más general y menos concreta" (TP, p. 124). No tenía, por tanto, que referirme a su carácter sacerdotal. El problema está planteado en términos de cristianismo y no en términos de sacerdocio. Más aún, lo que propongo como esencial a la solución tipo-Camilo Torres es "la lucha absoluta contra la violencia, la pasión fundamental por la justicia y la convicción de que las estructuras socio-económicas y políticas, por ser objetivación del ministerio de iniquidad tal como se presentan en muchas partes, deben ser removidas, porque son impedimento real del amor cristiano y de la vida cristiana" (TP, p. 124). Que el intentar la remoción de esas estructuras por la fuerza pueda caber en casos límites dentro de las exigencias del cristianismo, me parece que se puede probar, al 
menos por la tradición secular de la Iglesia y de sus teólogos. Con todo, advierto en el mismo texto (cfr. supra 4.2.2.2 y 4.2.2.3) la necesidad de cautelas.

5.3.2.2. Con tan poca base como ésta no es posible sustentar crítica ninguna.

5.3.3. El crítico romano malinterpreta mi idea de que "el tema de la ética de la violencia desborda el propósito de mi trabajo, que pretende ser teológico. Pero no por teológico quisiera parecer evasivo" (TP, p. 126), cuando dice: "se puede observar: Un trabajo teológico, en el campo moral, no puede prescindir de la ética. En realidad el Autor pronuncia un juicio teológico moral, es decir, ético, sobre la licitud de la fuerza (que para él no significa violencia) con el fin de eliminar la injusticia, que es siempre sinónimo de violencia, cuando sea una injusticia grave" ("Nota', p. 7).

5.3.3.1. Lo que quiero decir, al afirmar que no entro en determinaciones éticas, porque mi trabajo es teológico, se desprende de lo que sostienen quienes han hablado de este punto, y que al parecer es desconocido por el crítico romano ( $c f r$. T. Rendtroff, "Politische Ethik oder "Politishe Theologie""; y W. Pannenberg, "Geschichtstatsachen und christliche Ethik", en Diskussion zur "politischen Theoligie", Mainz, 1969, pp. 217-230 y 231-246). Cuando digo que para pasar del planteamiento teológico no al juicio moral sino a la praxis se necesita una mediación ética, lo que digo es que aun siendo los principios claros y clara la inspiración y la dirección cristiana, no se pueden trasladar sin más a la praxis concreta sin la mediación de unos esquemas y unos métodos, que ya no son propios de la teología. Se malentiende así mi trabajo, cuyo fin es el delimitar teológicamente qué es la violencia y cómo debe enfrentársela teológicamente. Qué hacer en la práctica para hacerla desaparecer, es una cuestión que no entra directamente en mi propósito. Para ello tendría que entrar en consideraciones que llamo éticas. Interpretar esto desde esquemas preconcebidos no hace sino mostrar una vez más las deficiencias de método que tiene el crítico romano.

5.3.3.2. No me voy a comparar con la prudencia cristiana que admira mi crítico en la Conferencia Episcopal de México. Pero me parece que estamos hablando de cosas distintas. Tendría que compararse detalladamente qué entiende la Conferencia por contra-violencia con lo que yo entiendo por resistencia a la violencia en sus diversas formas posibles. Aquí de nuevo sería oportuno considerar el problema de las mediaciones éticas para llevar a la práctica lo que debe ser en cada caso la resistencia adecuada a la violencia o si se prefiere la lucha activa contra toda forma de violencia. Los que apelan a la Conferencia Episcopal de México debieran comparar esta posición actual, con la que mantuvo gran parte de aquel Episcopado con ocasión de la Revolución mexicana. Las cosas vistas in situ e in historia son algo más complicadas de lo que parece apreciar el crítico desde Roma. 


\section{Conclusión de la Nota}

6.1. La conclusión de la 'Nota' dice así: “Teología Política del Rev. P. I. Ellacuría no ameritaba la publicación de parte del Secretariado Social Interdiocesano, para conmemoración del X Aniv. de la Enc. Pacem in Terris, ni el 'Puede imprimirse' de parte del Excmo. Mons. Arturo Rivera Damas, por motivo del contenido doctrinal, que frecuentemente está en contraste con importantes enseñanzas de la divina revelación, del Magisterio de la Iglesia y de la sana teología. Es deseable que en la América Latina semejantes publicaciones, no conformes del todo con la enseñanza del Episcopado y del Magisterio Conciliar y Pontificio, no reciban aprobación; de otro modo provocarán disensiones aun sobre verdades fundamentales, hasta en el clero y en el episcopado" ('Nota', p. 7).

6.2. Ante todo, es oportuno atender a ciertas consideraciones formales de esta conclusión:

6.2.1. En el texto transcrito Episcopado se escribe una vez con mayúscula y otra con minúscula, lo que hace sospechar que las ocho últimas palabras han sido añadidas al texto original. Hay otros indicios que apuntan a lo mismo.

6.2.2. En el mismo texto de la conclusión se dicen dos afirmaciones no del todo coherentes entre sí: (a) el contenido doctrinal está frecuentemente en contraste con importantes enseñanzas... y (b) no está conforme del todo con la enseñanza... Una de dos: o el contraste no significa más que no estar conforme del todo, lo cual no parece ser lógicamente equivalente, o en unas pocas líneas se indica el poco rigor de las expresiones.

6.2.3. La Conclusión no solo está mal apoyada objetivamente, como ya se ha mostrado y enseguida volveré a indicarlo, sino que desborda las formulaciones mismas del teólogo romano. Este dice a propósito de las dos críticas principales: "son dos las críticas principales que parece se pueden hacer" ("Nota', p. 2), y a propósito del único punto en que apela a la revelación su expresión es hipotética: "si se pone en duda" ("Nota', p. 6).

6.3. Las razones aludidas en la Conclusión carecen de fundamento:

6.3.1. No ha probado el crítico romano que el contenido doctrinal del trabajo esté en contraste con importantes enseñanzas de la divina revelación, del Magisterio de la Iglesia, y de la sana teología:

6.3.1.1. Por lo que toca a la divina revelación su alusión más explícita es el carácter oblativo de la redención de Cristo. Ya se ha mostrado (cfr. 5.2.4 hasta 5.2.4.4) cómo su objeción carece de fundamento.

6.3.1.2. Por lo que toca al Magisterio de la Iglesia. La referencia al Concilio de Calcedonia carece de sentido ( $c f r .5 .1 .2)$. Carece de base su referencia a Pío $X$ (cfr. 5.1.4.2). Su referencia a la Humanae vitae no invalida mi planteamiento 
(cfr. 5.2.1). Los planteamientos sobre la violencia no están en contraste con 1o que enseña el Magisterio ( $c f r$. 5.3.1 hasta 5.3.3.2).

6.3.1.3. Por lo que toca a la sana teología más vale no hablar, porque la teología de la que ha hecho uso el crítico romano más bien brilla por su ausencia y está muy lejos en calidad y contenido de la que hoy manejan los teólogos de mejor nota. Por otro lado, el desconocimiento del crítico romano en lo que toca a la teología latinoamericana es, por lo que se ve en este caso, sencillamente descomunal.

6.4. El análisis objetivo de la 'Nota' muestra fallos tan notorios, que la tal 'Nota' no ofrece base moral ni base ética para llegar a esa Conclusión:

6.4.1. Son tales los errores metodológicos y lógicos en los que incurre, que el escrito carece de toda autoridad científica $(c f r .4 .2 .1 .1 ; 4.2 .2 .1$ respecto de la traducción española; 4.2.2.5; 4.3.1; 5.1.1; 6.2.2; 6.2.3).

6.4.2. Me hace decir cosas que no sostengo, desfigura con frecuencia mi pensamiento y no tiene en cuenta la totalidad de lo que en el escrito se dice ( $c f r$. 4.2.1.2; 4.2.1.3; 4.2.1.4; 4.2.1.5; 4.2.1.7; 4.2.1.8; 4.2.2.2; 4.2.2.3; 4.2.2.4; 4.3.3; 4.3.3.1; 4.3.3.2; 5.1.2; 5.1.3; 5.1.4.2; 5.3.3; 5.3.3.1).

6.5. El crítico romano desfigura globalmente el status quaestionis de varios temas en particular y, lo que es más importante, del conjunto del trabajo. Con 1o cual sus observaciones particulares tienen que estar necesariamente desenfocadas:

6.5.1. En el texto mismo de mi análisis he señalado lugares de desenfoque del status quaestionis (cfr. 5.1.7; 5.2.4.1).

6.5.2. Pero el error de base está en desconocer el sentido preciso de lo que es la "Teología Política". La "Teología Política" tiene por una de sus finalidades principales la de mostrar la dimensión pública y social de las distintas afirmaciones teológicas y aun de todo el depósito de la fe. Presupone la totalidad del mensaje, pero hace de él una hermenéutica y una aplicación que en alguna manera resultan parciales. Por otra parte, la "Teología Política" tiende a presentarse como una nueva forma de Teología Fundamental. Como tal se esfuerza en hacer creíbles a Cristo y a la Iglesia respecto de un mundo histórico a quien ciertas presentaciones de Cristo y de la Iglesia le resultan increíbles. Mi trabajo muestra hasta la saciedad su intento de hacer creíble en la línea de la Teología Fundamental a Cristo y a la Iglesia. Pues bien, esta orientación decisiva de todo mi escrito parece haber escapado al crítico romano, que, además, en ningún caso muestra conocer la inundatoria bibliografía que hay sobre este tema.

6.6. La Conclusión ignora que los trabajos sobre la violencia y sobre la Iglesia como signo de credibilidad (de los que están tomadas las críticas más graves) estaban anteriormente publicados en escritos sancionados por la jerarquía ecle- 
siástica de fuera del país con censores bien severos. Más aún, el segundo de los trabajos está publicado sin mi firma y responsabilizado directamente por una comisión jerárquica nacional de un país de gran tradición católica y de muy abundante jerarquía. Atrevido parece, por tanto, el crítico romano o el redactor de la Conclusión cuando encuentra tan graves errores, según él.

6.7. Fácil sería probar cómo mucha y cualificada parte del Episcopado del Tercer Mundo está en la misma línea que la propugnada en mi trabajo. Y no veo que esto promueva disensiones sobre verdades fundamentales, a no ser entre Obispos y Clero que están al margen de lo que supuso Medellín para Latinoamérica.

\section{Consideraciones finales}

7.1. La 'Nota' podría haber servido como instrumento de crítica y de mejora del trabajo Teología Política, y, si de eso hubiera servido, habría prestado gran utilidad. No ha sido así. La precipitada lectura y falta de comprensión del texto que trasluce, la falta de conocimiento de bibliografía especializada, incluso el desconocimiento de lo que es la teología política, hacen que su utilidad científica sea prácticamente nula.

7.2. La 'Nota' podría haber servido para entablar un diálogo que ayudase a poner en claro posibles malentendidos doctrinales o pastorales. Pero para esto se hubiera requerido un esfuerzo primero de acomodación y una petición de explicación, allí donde se hubiera podido tropezar en el texto. Nada de esto ha hecho el crítico.

7.3. ¿A qué intereses responde, por tanto, la petición de la 'Nota' y su consiguiente publicidad?

7.3.1. Pudiera responder al interés de quienes pueden ver en el trabajo un peligro para la orientación del Cristianismo aquí y ahora, tal como ellos lo entienden.

7.3.1.1. Si es así, el recurso inmediato a Roma implica una gran pobreza intelectual, una negación del diálogo teológico y un ataque a la libertad de investigación. Roma puede ser un último recurso y no un recurso primero, si es que pretendemos que las Iglesias locales alcancen la mayoría de edad que les corresponde.

7.3.1.2. Curiosamente los que muestran ese tipo de interés representan también una determinada posición política: la de evitar a toda costa lo que pudiera suponer, aun de lejos y desde perspectivas cristianas, un intento de cambio radical. Se trata, pues, de una acción política o de consecuencias inmediatamente políticas.

7.3.2. Una pregunta obvia es a quién sirve este tipo de publicaciones o, al menos, quién saca partido de ellas. La lectura de los periódicos nacionales lo aclara: a los defensores más recalcitrantes del capitalismo.

7.4. La 'Nota', tanto por lo que tiene de calidad técnica como por el modo en que ha sido presentada, no puede menos de incidir en menoscabo de la Santa 
Sede y de la Conferencia Episcopal de El Salvador. Si el trabajo Teología Política se consideraba importante, hubiera necesitado un crítico más capaz; si no se lo consideraba importante, no era necesario haber hecho tanto alboroto.

7.5. La intencionalidad de la 'Nota' puede vislumbrarse del hecho de que los méritos reconocidos al trabajo no hayan entrado para nada en la conclusión. Más aún, en estos méritos no se hace hincapié en la utilidad, hoy claramente reconocida en Latinoamérica, de este tipo de estudios y, sobre todo, en la nueva orientación teológica y en el nuevo instrumental utilizado. El aporte de Roma al perfeccionamiento de este tipo de trabajos no parece debe ser el seguido en este caso. Tal cúmulo de incomprensiones no puede llevar a nada bueno. Ojalá no sea éste el modo habitual de proceder por el bien de la unidad de la Iglesia. 